\title{
Inclusión de los delitos ambientales en el Código Penal argentino ${ }^{1}$
}

\section{Inclusion of environmental crimes in the Argentine Penall Code}

\section{María Alejandra Cau Cattán, Rosa Inés Torres Fernández y Jorge Luis Villada²}

\section{Resumen}

El derecho ambiental refleja la preocupación que tiene el ser humano por el entorno natural que le brinda las condiciones externas para el desarrollo de la vida, en virtud de lo cual surgen una serie de instrumentos internacionales. Nuestro Código Penal no contiene una figura especial referida al daño ecológico como tipo delictivo, sino que sanciona los supuestos de envenenamiento de aguas o sustancias alimenticias o medicinales, pero no contempla los casos de menoscabos a la atmósfera, a los suelos, etc. Por tal motivo, teniendo en cuenta que en el Congreso de la Nación está previsto el tratamiento de la reforma del Código Penal, consideramos que

\begin{abstract}
Environmental law reflects the concern that human beings have for the natural environment that provides the external conditions for the development of life, by virtue of which a series of international instruments have emerged. Our Penal Code does not contain a special figure referring to ecological damage as a type of crime, but sanctions cases of poisoning of food or medicinal water or substances; although it does not cover cases of damage to the atmosphere, soil, etc. For this reason, given that the Congress of the Nation is considering the treatment of the reform of the Penal Code, we consider that the inclusion
\end{abstract}

\section{Derecho/ artículo científico}

Citar: Cau Cattán, M. A.; Torres Fernández, R. I.; Villada, J. L. (2021). Inclusión de los delitos ambientales en el código penal argentino. Omnia. Derecho y sociedad, 4 (4), pp. 55-77.

\footnotetext{
'El presente artículo es resultado del proyecto de investigación "Inclusión de los delitos ambientales en el Código Penal argentino", aprobado por Resolución Rectoral 1361/18. Fue generado en el ámbito del Instituto de Derecho Ambiental y de la Sustentabilidad (IDEAS) y del Instituto de Ciencias Penales, Sociales y Afines, ambos de la Universidad Católica de Salta. El equipo de investigación estuvo conformado por Jorge Luis Villada (director), Rosa Inés Torres Fernández, María Alejandra Cau Cattán y Maximiliano Villada Alday; y los estudiantes dela carrera de Abogacía: Nicolás Colombres, Salomé Sánchez y Fabián Galli.
}

${ }^{2}$ María Alejandra Cau Cattán. Abogada. Master en Gestión de Biodiversidad. Maestranda en Criminología Ambiental de la Escuela Internacional de Criminología y Criminalística de España. Miembro del Instituto de Derecho Ambiental y de la Sustentabilidad de la UCASAL. Vicepresidente del Instituto de Derecho Ambiental del Colegio de Abogados de Jujuy. Exdirectora de Energías Renovables y Eficiencia Energética de la provincia de Jujuy. acaucattan@gmail.com

Rosa Inés Torres Fernández. Abogada y Procuradora, egresada de la UNC. Profesora en Ciencias Jurídicas, egresada de la UNSa. Magister en Gestión Ambiental por la UCASAL. Miembro del Instituto de Derecho Ambiental y de la Sustentabilidad de la UCASAL, del Instituto de Ciencias Penales, Sociales y Afines de la UCASAL y del Instituto de Derecho Ambiental del Colegio de Abogados de Salta. Investigadora asociada «D» de la UCASAL. ORCID: https://orcid.org/00000002-0209-3867. rosaitf23@gmail.com

Jorge Luis Villada. Abogado. Especialista en Derecho Penal por la UCASAL. Ex Juez de la Cámara Federal de Salta. Director del Instituto de Ciencias Penales, Sociales y Afines de la UCASAL. Docente de las cátedras de Derecho Penal General y Derecho Penal Especial de la UCASAL. Investigador independiente «B» de la UCASAL. villadajorge@hotmail.com 
la inclusión de los delitos ambientales es de suma necesidad y urgencia, dado que existen numerosos fallos consecuencia de planteos por incumplimiento de leyes y principios ambientales.

Palabras clave: delitos ambientales - contaminación - ecocidio - criminalización - responsabilidad of environmental crimes is of utmost necessity and urgency, given that there are numerous rulings as a consequence of claims for non-compliance with environmental laws and principles.

Keywords: environmental crimes - pollution ecocide - criminalization - liability

\section{INTRODUCCIÓN}

El Instituto de Derecho Ambiental y de la Sustentabilidad conjuntamente con el Instituto de Ciencias Penales, Sociales y Afines, ambos dependientes de la Facultad de Ciencias Jurídicas, presentaron ante la Universidad Católica de Salta el proyecto de investigación «Inclusión de los delitos ambientales en el Código Penal argentino», aprobado por Resolución Rectoral 1361/18. El presente artículo es producto del informe final de dicho proyecto de investigación.

El equipo estuvo integrado por el doctor Jorge Luis Villada (director) y los abogados Rosa Inés Torres Fernández, María Alejandra Cau Cattán y Maximiliano Villada Alday. Además, participaron los alumnos Nicolás Colombres, Salomé Sánchez y Fabián Galli.

Se trata de una investigación descriptiva de enfoque cualitativo sin anticipaciones de sentido o hipótesis, porque funciona como primera aproximación a la materia con el objetivo de caracterizar el área temática contextualizándola en la República Argentina. La metodología cualitativa de la investigación incluyó la aplicación de herramientas y estrategias tales como el análisis comprensivo de las diferentes legislaciones nacionales e internacionales, el análisis de documentos y el análisis de contenido.

Además, su objetivo general consiste en proponer la inclusión de figuras penales tipificando los delitos ambientales; es un proyecto para enviar como propuesta de la Universidad Católica de Salta al Congreso de la Nación para la inclusión de tales ilícitos específicos en el Código Penal argentino. Como objetivo específico se encuentra la tipificación de los delitos ambientales, describiendo para ello las conductas y las penas correspondientes.

\section{CONCEPTO DE AMBIENTE}

El ambiente o medioambiente es abarcativo de los elementos naturales, sociales, culturales, arquitectónicos, paisajísticos y urbanísticos. Para Libster y Crea (2019) no es una mera acumulación de elementos, sino un sistema integrado que tiene un punto natural de equilibrio.

\section{CONCEPTO DE DERECHO AMBIENTAL}

El concepto de derecho ambiental que acuña o recoge cada autor está directamente relacionado con el momento en la evolución del derecho en el que él o ella se desarrolla, con la característica de haber comenzado o no su carrera profesional como especialista en ambiente, o con si tiene una base en otras ramas del derecho; con lo cual teñirá toda su construcción doctrinaria con esa mirada, pero esta también estará condicionada por su ideología y su forma de concebir el mundo y la naturaleza, así como sus interrelaciones.

Brañes (2000), en su Manual de derecho ambiental mexicano, define el derecho ambiental como a aquel conjunto de reglas que 
se ocupan de la protección jurídica de aquellas condiciones que hacen posible la vida, en todas sus formas. Valls (2008), en su libro Derecho ambiental, afirma que el derecho ambiental es aquel que norma la creación, modificación, transformación y extinción de las relaciones jurídicas que condicionan el disfrute, preservación y mejoramiento del ambiente en la medida en que hace posible la vida de todas las especies sobre la Tierra.

En este sentido, Asturias (2018) expresa que el derecho ambiental aparece hoy como una saludable esperanza en la lucha por la preservación de la vida en nuestro planeta, y para ello le resulta forzoso nutrirse de una multiplicidad de sectores del ordenamiento jurídico, que ineludiblemente deberá relacionarse transversalmente con casi todas las ramas del derecho.

A su vez, Libster y Crea (2019) manifiestan que la incorporación de la variable ambiental a las reglas del derecho vino a concretar el reconocimiento de criterios, valores y principios que fueron transformándose en instituciones reconocidas por el derecho, y finalmente en las instituciones del derecho ambiental.

Por último, y siguiendo a Prieur (2012) en su obra El nuevo principio de no regresión en derecho ambiental, afirmamos que el derecho ambiental no se trata simplemente del conjunto de normas jurídicas que delimitan el medioambiente, sino que es la expresión de una ética o de una moral del medioambiente que pretende reducir la contaminación y aumentar la biodiversidad.

Desde su criterio, el cual está de acuerdo con nuestro criterio doctrinario, el derecho ambiental no constituye solamente un derecho que regula actividades de forma neutra, sino que se trata de un derecho comprometido con la lucha contra la contaminación y la pérdida de biodiversidad; el perfilado del derecho ambiental, su conceptualización, su de- finición debe hacerse con un criterio finalista, como aquel que, debido a su contenido, contribuye a la salud pública y al mantenimiento de los equilibrios ecológicos, esto es, un derecho para el medioambiente.

\section{CONCEPTO DE DELITOS AMBIENTALES}

El delito ambiental es aquella conducta que se encuentra descripta en un tipo penal específico, sancionado con penas privativas de libertad (y eventualmente de inhabilitación y/o de multa, las que se pueden aplicar conjunta o alternativamente), por cuanto dichos comportamientos implican material (o formalmente) graves daños al medioambiente, con consecuencias negativas o dañosas para las personas en particular, la salud de la población y su calidad de vida, o de la flora, fauna, la alteración de los ecosistemas o que representen un peligro para los bienes enunciados, sea que se lleven a cabo de manera dolosa o culposa.

Es decir, que el delito ambiental es un modo distintivo de atacar a la vida, a la salud, a la supervivencia de las especies y a la conservación deseable e imprescindible del ambiente natural, teniendo en miras aquellos valores. Pero, además, con base en lo expuesto, tanto desde el punto de vista científico penal (dogmático) como de la política criminal de un Estado, la característica esencial es que estos delitos como los demás regulados en la ley de fondo (que pertenecen al campo del derecho penal común) interesan a toda la sociedad. Se trata de proteger así, los intereses comunes a toda la Nación y quienes la habitan. Por ello deben preverse en una legislación de fondo como el Código Penal.

Ello deja a las provincias (por nuestro sistema federal), la facultad de creación de contravenciones, que son infracciones de carácter local e igualmente contienen un sistema de 
sanciones o medidas asegurativas, más diversificadas que las penas (del Código Penal), permitiendo así elucubrar un sistema de reacción estatal más rico y variado que no signifique necesariamente un «castigo», sino que hasta puede tener carácter preventivo. La contravención es esencial para «prevenir delitos» y su aplicación se puede ramificar a todo el espectro provincial, permitiendo su aplicación hasta por jueces de paz.

\section{ANTECEDENTES}

Para la elaboración del presente trabajo de investigación se consideraron diversos antecedentes que existen en torno a la protección del medioambiente. En el plano internacional la evolución del derecho ambiental se da en el marco de convenciones internacionales y trabajos en el interior de organismos internacionales como las agencias de la Organización de las Naciones Unidas (ONU). Está dado por un conjunto de declaraciones, tratados y normas, tanto vinculantes como voluntarias, que se han desarrollado a la par del conocimiento científico y de la toma de conciencia del estado actual de nuestro mundo natural.

El derecho internacional público ambiental podría separarse en tres etapas, separadas por dos hitos producidos en dos convenciones internacionales: la Conferencia de Estocolmo de 1972 y la Convención de Río de Janeiro de 1992. En el último tiempo, el hito más relevante fue la firma del Acuerdo de París en 2016, y el acuerdo de Escazú recientemente ratificado por la República Argentina y que ya cuenta con los 11 países necesarios para su entrada en vigencia, con lo que una vez depositados los documentos, la tendrá de manera plena.

Una primera etapa podemos decir que empieza en el año 1900, cuando se intenta por primera vez firmar un acuerdo internacional para la preservación de un elemento del ambiente, que en este caso era la vida silvestre africana. Durante esos años no existía mayor conciencia sobre la fragilidad de la naturaleza y el posible agotamiento de algunos de sus recursos. Por el contrario, la «naturaleza» era concebida como algo que había que dominar, que lograr controlar al servicio de las necesidades humanas. Así es que la Convención de Londres de 1900 no logró suficiente cantidad de firmas. Sin embargo, al mismo tiempo empezaba a surgir la idea de que los recursos no eran infinitos ni renovables ilimitadamente sino que, por el contrario, si se les aplicaba demasiada presión o se los explotaba indiscriminada e ilimitadamente, estos empezaban a mutar y a desaparecer. Así, esta etapa estuvo caracterizada por la preservación de recursos naturales, flora, fauna, especies, y de hábitats de singular interés de protección.

Más de 30 años después se vuelve a redactar un convenio en Londres, en 1933, que logró la adhesión y vigencia en los países que formaban parte de las colonias europeas en África, constituyéndose áreas protegidas y poniendo límites a la extracción de especies. Más tarde, entraron en vigencia instrumentos como la Convención de Washington de 1940 y el Convenio de la Paz de protección de la vicuña de 1969, siempre en torno a la protección de especies, hábitats y recursos naturales en general, creándose organismos internacionales en el seno de las Naciones Unidas, como la FAO (Food and Agriculture Organization), la Organización de las Naciones Unidas para la Educación, la Ciencia y la Cultura (UNESCO), el Programa de Naciones Unidas para el DesarroIlo (PNUD), etc.

Así continuaron esfuerzos aislados, hasta que en la última parte de la década del 1960 y principios de 1970 se da un florecimiento de la conciencia y el inicio de los movimien- 
tos «verdes» que continúan hasta hoy. En ese marco, como producto de la 1. a Conferencia de Naciones Unidas Sobre Ambiente Humano, surge la Declaración de Estocolmo de 1972 y por primera vez vemos un instrumento jurídico que se refiere al derecho al ambiente sano y la creación del Programa de Naciones Unidas para el Medioambiente (PNUMA) y comienza a desarrollarse con mayor vigor el trabajo de las principales organizaciones no gubernamentales internacionales que tienen por fin la protección del medioambiente, como la World Wildlife Fund (WWF), Greenpeace, y la Unión Internacional para la Conservación de la Naturaleza (UICN).

Este movimiento tiene un punto de vista antropocéntrico desde donde se toma conciencia de los productos y servicios ambientales: la naturaleza debe preservarse en función de las necesidades de supervivencia del ser humano y la manutención de los niveles de vida y producción. Entre la sanción del Convenio de Estocolmo y el siguiente hito que estará dado por la Convención de Río, encontramos el surgimiento de los primeros partidos políticos verdes y la creación de áreas en los Estados nacionales dedicadas específicamente a la gestión ambiental, que en nuestro país se tradujo en la designación de Yolanda Ortiz, en 1972, como la primera secretaria de Recursos Naturales y Ambiente Humano (aquí ya se puede notar claramente el enfoque antropocéntrico de la época).

La Convención RAMSAR de 1971 es el primer instrumento internacional de conservación integral de un hábitat, que en este caso son los humedales de importancia internacional. La segunda etapa está signada por una mirada antropocéntrica de la protección ambiental, donde encontramos instrumentos tan importantes como la Declaración de Estocolmo de 1972, que se sanciona en el marco de la conferencia de Naciones Unidas para el ambiente humano, la redacción de la Carta Mundial de la Naturaleza de 1982 y, sobre todo, del Informe Brundtland - Nuestro futuro común- como fruto de la creación de la Comisión Mundial sobre Medioambiente y el Desarrollo en el marco de Naciones Unidas en 1983, que echa las bases para la Convención de Río de Janeiro de 1992 donde se termina de sancionar a nivel internacional el concepto de «desarrollo sostenible como superador de la dicotomía producción o conservación del medioambiente». Este es receptado en las constituciones del mundo en un movimiento vigorosamente constitucionalizador de la temática ambiental sin precedentes en el planeta. Así, el desarrollo sostenible se concibe como el desarrollo que satisface las necesidades de la generación presente sin comprometer la capacidad de las generaciones futuras para satisfacer sus propias necesidades.

Allí se encuentran incluidos elementos morales como son la solidaridad, los valores sociales y la equidad, los bienes presentes pueden ser utilizados para satisfacer las necesidades de la generación presente, pero ese uso y goce debe ser adecuado ya que no se pueden agotar los bienes presentes en detrimento de la satisfacción de las necesidades de las generaciones futuras. Al respecto, Ángeles Cuadrado Ruiz afirma:

Creo que la ecología ha dejado de ser una mera instancia bucólica o la expresión pacifista de la contestación política. Esta «conciencia ecológica» ha de favorecerse, toda vez que, para el desarrollo de una sociedad pacífica, no pocos valores éticos tienen una relación tan directa con la cuestión ambiental (...). La descripción que se hace en el artículo 340 sigue en los aspectos fundamentales al modelo alemán (...) la reparación 
del daño y del daño medioambiental ha de situarse en un primer plano de los objetivos político criminales (Cuadrado Ruiz, 2010).

Posteriormente, en 1987 se firma el Protocolo de Montreal, que tenía por finalidad esencial detener el agotamiento de la capa de ozono. Este es un ejemplo de lo que la cooperación integral puede hacer cuando logra acuerdos realmente vinculantes y acatados por los países signatarios. En 1992, durante la Cumbre de la Tierra en Río también se firman el Convenio sobre la Diversidad Biológica y la Convención marco de Naciones Unidas sobre cambio climático; se reafirma la Declaración de Estocolmo mediante la Declaración de Río y se sanciona la Agenda 21 como programa de acción ambiental que guiará a los Gobiernos en las políticas públicas ambientales. Aquí se menciona por primera vez el «principio precautorio», la necesidad de participación, el derecho a la información ambiental y a la justicia ambiental. De varios de estos principios surgen luego otros acuerdos; por ejemplo, con respecto al principio $10 .^{\circ}$ surge el Convenio de Aarhus, que es vinculante para Europa y Asia Central, y es el antecedente del Acuerdo de Escazú que haría lo propio para Latinoamérica.

A partir de Río, la protección ambiental pasa a ser una consideración ineludible en todos los acuerdos internacionales de otras temáticas, y estarán signadas por la idea de «sostenibilidad ambiental».

En 1995 la Convención sobre Cambio Climático inicia su actividad, que continúa hasta nuestros días. En 1997 se sanciona el Protocolo de Kioto que impone obligaciones jurídicamente vinculantes para los países signatarios, respecto de la reducción de emisiones (en este caso, de los países desarrollados) receptando principios de Río, como fue el de la responsabilidad común respecto de la preservación del medioambiente pero diferenciada, reconociendo la necesidad de los países en desarrollo de lograr crecimiento, erradicación de la pobreza, etc. Se decía que los países desarrollados habían llegado a ser lo que eran con base en una externalización de los costos ambientales de su desarrollo, y que entonces ahora era el momento de apoyar el crecimiento y desarrollo de los otros países o no sería posible exigirles que no explotaran sus recursos naturales en pro de un futuro común. La línea de investigación y doctrina internacional que surge a raíz del Protocolo de Kioto nos lleva hasta el Acuerdo de París de 2016.

En el año 2000 ve la luz la Declaración del Milenio, que es realizada por 189 países, y se sanciona también el Protocolo de Cartagena sobre Seguridad de la Biotecnología del Convenio sobre la Diversidad Biológica, que es un instrumento internacional destinado a regular los organismos vivos modificados, producto de la biotecnología moderna. Justamente, en el artículo $1 .^{\circ}$ del Protocolo de Bioseguridad, el objetivo primordial es garantizar un nivel adecuado de protección en la esfera de la transferencia, manipulación y utilización seguras de los organismos vivos modificados resultantes de la biotecnología moderna que puedan tener efectos adversos para la conservación y la utilización sostenible de la diversidad biológica, teniendo también en cuenta los riesgos para la salud humana, y centrándose concretamente en los movimientos transfronterizos.

En 2002 se adopta la Declaración sobre Desarrollo Sostenible en el marco de la Cumbre Mundial de Naciones Unidas sobre Desarrollo Sostenible en Johannesburgo, donde se reafirman los compromisos de Río, pero se menciona expresamente la necesidad de luchar contra la pobreza, y es cuando los objetivos de desarrollo sostenible se amplían a lo que hoy conocemos como los Objetivos de Desa- 
rrollo del Milenio, donde vemos reflejada la interconexión que existe entre conservación del medioambiente, desarrollo, equidad, inclusión, y pobreza.

En 2010 se sanciona el Protocolo de Nagoya sobre protección de ecosistemas, especies y recursos genéticos.

En 2012 Naciones Unidas organiza la llamada Río+20, con representantes de todos los sectores, tanto públicos como privados, y del tercer sector. Se elabora la carta «El futuro que queremos», renovando el compromiso planetario con el desarrollo sostenible.

De este antecedente surge el informe que contiene las principales recomendaciones del Grupo de Trabajo de Naciones Unidas para la Agenda de Desarrollo Post 2015, entregado al secretario general de Naciones Unidas. En enero de 2012, el secretario general creó este grupo de trabajo para coordinar el apoyo del Sistema de Naciones Unidas a la discusión sobre la agenda de desarrollo post 2015, en consulta con todos los actores. Este grupo de trabajo está integrado por expertos identificados por los responsables de más de 50 organizaciones del Sistema de Naciones Unidas y otras organizaciones internacionales.

El principal reto de la agenda de desarrollo post 2015 es asegurar que la globalización se convierta en una fuerza positiva para todos los habitantes del mundo en esta generación y en las generaciones del futuro. La globalización ofrece grandes oportunidades, pero sus beneficios, en este momento, se distribuyen de manera muy desigual. La búsqueda continua por mejorar el bienestar material de la gente amenaza con sobrepasar los límites materiales del planeta, a menos que haya un cambio radical hacia patrones de consumo y de producción sostenibles en relación al uso de los recursos naturales. Las desigualdades existentes y la lucha para acceder a recursos naturales esca- sos son determinantes clave de situaciones de conflicto, hambre, inseguridad y violencia que, a su vez, frenan el desarrollo humano y los esfuerzos para lograr un desarrollo sostenible. La continuación de esta inercia no es una opción, es necesario un cambio transformador.

En los últimos años empezamos a ver reflejados en la jurisprudencia local de los países los principios y criterios de estos acuerdos internacionales. Se puede notar cómo en el interior de los países el desarrollo sostenible cobra cada vez mayor relevancia y se empieza a reconocer al derecho al ambiente sano como un «derecho humano».

Específicamente para Latinoamérica, resultó esencial y determinante la Opinión Consultiva 23 , de 2017, donde la Corte Interamericana de Derechos Humanos reconoció por primera vez «el derecho al ambiente sano como fundamental para la existencia humana». Este enorme esfuerzo internacional ha sentado las bases para un desarrollo sostenible que aún no se ve reflejado en los modelos de gestión y producción en el interior de los países, y para ello se requiere un trabajo intenso en el derecho público interno. La reforma del Código Civil argentino es un preciso ejemplo de esto, y creemos que es momento de hacer lo propio con el Código Penal, sancionando tipos penales que reflejen la importancia que da la sociedad a la protección del bien jurídico ambiente, como puede verse en los últimos movimientos de la sociedad civil argentina, y en la jurisprudencia de su máximo tribunal, respetando los principios de legalidad, racionalidad, última ratio, lesividad, humanidad, protección y defensa social e individual y demás, incorporados por el bloque de convencionalidad a nuestro sistema constitucional. Pero, a la vez, sin descuidar legislar en forma complementaria, en materia contravencional y de faltas (a nivel provincial y municipal).

Omnia. Derecho y sociedad, núm. 4, 2021: 55-77 e-ISSN 2618-4699 
Nuestro sistema jurídico no escapa al desarrollo global con base en el reconocimiento de los Derechos Humanos y la regulación de los avances industriales y comerciales; los derechos de tercera generación se profundizan y responden a un derecho moderno que se especializa. Además, podemos ver que la Constitución de la Nación Argentina a partir de la reforma del año 1994 comprende el «derecho a un medioambiente sano», contemplando la degradación y el deterioro del ambiente, el uso y abuso de los recursos naturales, lo cual provoca un peligro para la supervivencia de los seres humanos y no humanos, que, al convertirse en un potencial daño generalizado para la Nación, incumbe en cuanto a su protección al derecho penal.

La Constitución Nacional eleva al medioambiente a la categoría de bien jurídico protegido esencial, a la categoría de un nuevo derecho-deber de los habitantes, y a un objetivo de políticas públicas. Regula el ambiente en función de más de un factor, incluyendo la salud, el equilibro ecológico o resiliencia de los sistemas, el cuidado y la protección de la diversidad biológica, del patrimonio natural y cultural, y de su utilización racional, más allá de los meros recursos naturales en general. Asimismo, consagra el amparo ambiental, el principio contaminador pagador $y$, finalmente, el federalismo ambiental de concertación como herramienta para la unificación de los mínimos de política ambiental en todo el territorio, mediante la colaboración legislativa entre la Nación (que debe dictar los presupuestos mínimos de protección) y las provincias (que complementan aquellos con leyes provinciales reglamentarias y preventivas), y la creación del Consejo Federal de Medioambiente (COFEMA) como órgano supraprovincial de concertación de la política ambiental nacional.
La raigambre, el fundamento y la justificación de las normas penales propuestas emanan del propio artículo 41 de la Constitución Nacional, el cual establece que

... todos los habitantes gozan del derecho a un ambiente sano, equilibrado, apto para el desarrollo humano y para que las actividades productivas satisfagan las necesidades presentes sin comprometer las de las generaciones futuras; $y$ tienen el deber de preservarlo. El daño ambiental generará prioritariamente la obligación de recomponer, según lo establezca la ley. Las autoridades proveerán a la protección de este derecho, a la utilización racional de los recursos naturales, a la preservación del patrimonio natural y cultural y de la diversidad biológica, y a la información y educación ambientales. Corresponde a la Nación dictar las normas que contengan los presupuestos mínimos de protección, y a las provincias, las necesarias para complementarlas, sin que aquéllas alteren las jurisdicciones locales. Se prohíbe el ingreso al territorio nacional de residuos actual o potencialmente peligrosos, y de los radiactivos.

Llegando ya al punto de este estudio, el cual tiene como principal objetivo el debate y la propuesta de inclusión de delitos, tipos penales, específicos en la temática ambiental (sin por ello desechar las normas contravencionales, técnicas o disciplinarias que deben complementar el espectro de protección legislativa), hemos extraído de estos instrumentos internacionales los contenidos relacionados directa o indirectamente a la sanción de delitos, a la referencia a conductas delictuales, 
donde se empieza a presentar la indiscutible necesidad de la intervención del derecho penal como última ratio.

\section{NORMATIVA PENAL INTERNACIONAL}

De igual manera procedimos respecto del derecho interno, rescatando y analizando las normas penales contenidas en la normativa ambiental sobre temas específicos como son las leyes de residuos peligrosos y de protección de fauna, entre otras sobre las que no abundaremos aquí. Asimismo, efectuamos una recopilación de los códigos penales o leyes de otros países (derecho comparado) que poseyeran un capitulo ambiental o una normativa específica sobre la protección penal del medioambiente, o contra la contaminación, o sobre la protección de la biodiversidad, entre otras cuestiones. Los principales insumos en materia de códigos penales de derecho comparado son:

- Código Penal de Alemania.

- Lei de Crimes Ambientais 9605 de la República Federativa de Brasil. Es uno de los textos legales más modernos y completos enfocados en los delitos ambientales.

- Código Penal de Bolivia. Ley del Medioambiente 1333/92.

- Código Penal de Colombia: los delitos contra los recursos naturales y medioambiente (artículos 328 a 339), los delitos contra la seguridad pública (artículos 358 y 379).

- Código Penal de España: los delitos contra los recursos naturales y el medioambiente (artículos 325 a 337); los delitos contra la seguridad colectiva (artículos 341 a 355); delitos contra la salud pública (artículos 359 a 367).

- Código Penal de Ecuador: los delitos contra la salud pública y el medioambiente (artículos 428 a 437).
- Código Penal de El Salvador: los delitos contra la contaminación ambiental (artículos 258 a 272).

- Código Penal de Francia.

- Código Penal de Guatemala: los delitos contra la salud pública (artículos 301 a 312), propagación de enfermedades en plantas o animales (artículos 344 a 345); explotación ilegal de recursos naturales (artículos 346 a 347).

- Código Penal de Honduras: delitos contra la salud pública (artículos 180 a 190).

- Código Penal Federal de México: los delitos contra el ambiente y la gestión ambiental (artículos 414 a 423).

- Código Penal de Nicaragua: los delitos contra la salud pública, contaminación ambiental, caza de animales en peligro de extinción, etc. (artículos 330 a 391). Ley Especial de Delitos contra el Ambiente y los Recursos Naturales 559/05.

- Código Penal de Panamá: los delitos contra la salud pública (artículos 304 a 311), los delitos contra el ambiente (artículos 399 a 421).

- Código Penal de Paraguay: Ley 1160/97. Ley $716 / 96$, que sanciona los delitos contra el ambiente.

- Código Penal de Perú: los delitos contra la salud pública (artículos 286 a 289), la violación de medicinas sanitarias y venta de animales de consumo peligroso (artículos 292 y 293), delitos ambientales (artículos 304 y siguientes, 312 y siguientes).

- Código Penal de Puerto Rico: el incendio forestal (artículo 232).

- Ley 64/00 República Dominicana. Medioambiente y Recursos Naturales.

- Código Penal de Uruguay: los delitos contra la salud (artículos 218 a 225).

- Ley Penal del Ambiente de la República de Venezuela.

Omnia. Derecho y sociedad, núm. 4, 2021: 55-77 


\section{NORMATIVA ARGENTINA}

Tal como se señaló precedentemente, en la normativa interna de nuestro país encontramos legislación penal ambiental asistemática, la cual no constituye un solo cuerpo normativo cohesionado, debidamente sistematizado e integrado a las altas finalidades tuitivas propuestas sino que, por el contrario, toda esta normativa se encuentra diseminada en regulaciones de distinta índole y, en algunos casos, resultando un mero «derecho penal simbólico».

Así tenemos en nuestro Código Penal los delitos de daño y grandes estragos (arts. 184/186). En el art. 186 en su inc. $2 .^{\circ}$ se hace alusión específica a los bosques. Luego, y casi antojadizamente, existe un capítulo completo sobre delitos contra la seguridad y la salud pública (arts. 200/203), que trata los temas referidos al envenenamiento o adulteración de aguas potables o sustancias alimenticias o medicinales, a la venta o distribución de medicamentos o mercaderías peligrosas para la salud (arts. 186, 200/207), así como al delito de usurpación de aguas (art. 182).

En el Título VII de la Parte Especial (delitos contra la seguridad pública), una porción del extenso artículo 189 bis reza textualmente:

(1) El que, con el fin de contribuir a la comisión de delitos contra la seguridad común o causar daños en las máquinas o en la elaboración de productos, adquiriere, fabricare, suministrare, sustrajere o tuviere en su poder bombas, materiales o aparatos capaces de liberar energía nuclear, materiales radiactivos o sustancias nucleares, o sus desechos, isótopos radiactivos, materiales explosivos, inflamables, asfixiantes, tóxicos o biológicamente peligrosos, o sustancias o materiales destinados a su preparación, será reprimido con reclusión o prisión de cinco (5) a quin- ce (15) años. La misma pena se impondrá al que, sabiendo o debiendo saber que contribuye a la comisión de delitos contra la seguridad común o destinados a causar daños en las máquinas o en la elaboración de productos, diere instrucciones para la preparación de sustancias o materiales mencionados en el párrafo anterior.

En el artículo 194 del Código Penal, sin ningún criterio sistematizador y hasta mezclando indebidamente los bienes jurídicos protegidos, se dispone:

El que, sin crear una situación de peligro común, impidiere, estorbare o entorpeciere el normal funcionamiento de los transportes por tierra, agua o aire o los servicios públicos de comunicación, de provisión de agua, de electricidad o de sustancias energéticas, será reprimido con prisión de tres meses a dos años.

Véase que la protección de la provisión de agua (esencial para la vida de toda especie animal o vegetal), está incluida entre los medios de comunicación y transporte.

En el Capítulo VIII de la Ley Nacional 22421 de Protección y Conservación de la Fauna Silvestre encontramos otros tipos penales que sancionan específicamente acciones relacionadas a caza furtiva, depredación de la fauna silvestre, uso de armas prohibidas, y el comercio, transporte, acopio e industrialización de los productos provenientes de las mencionadas actividades.

Por su parte, la ley que ha sido el fundamento de la enorme mayoría de las sentencias relacionadas con la temática ambiental en nuestro país, que es la Ley n. 24051 de Residuos Peligrosos, establece cláusulas referidas a la responsabilidad penal aplicable a la gene- 
ración, manipulación, transporte, tratamiento y disposición final de residuos peligrosos, y en su capítulo IX prevé sanciones para quien mediante el uso de estos residuos «envenenare, adulterare o contaminare de un modo peligroso para la salud, el suelo, el agua, la atmósfera o el ambiente en general». Claramente se trata de un tipo penal doloso, lo que se ve reforzado por la fórmula de redacción empleada en el artículo 56, que contempla la figura culposa para los casos en que la conducta típica se cometiere «por imprudencia o negligencia o por impericia en el propio arte o profesión o por inobservancia de los reglamentos u ordenanzas (...)». Es la ley que en nuestro país establece la responsabilidad de los directivos de las personas jurídicas cuando los delitos se hubiesen producido por decisión de estos últimos.

Finalmente, nuestro Código Procesal Penal Nacional dispone que los delitos susceptibles de menoscabar el medioambiente son de acción pública, lo que lleva implícita la posibilidad de la denuncia sin legitimación o capacidad especial, como así también la actuación de oficio.

Se observa así la necesidad de aglutinar en un cuerpo específico de normas toda forma de ataque (delictivo) al ambiente y demás bienes jurídicos relativos a este que ponga en grave riesgo la vida humana, tanto de las presentes como de las futuras generaciones.

En cambio, obsérvese el caótico panorama legislativo en relación a la materia ambiental, que presenta nuestro país, en la siguiente enumeración no exhaustiva de nuestra normativa vigente:

\section{a. Leyes}

- Ley Nacional 26639. Régimen de Presupuestos Mínimos para la Preservación de los Glaciares y del Ambiente Periglacial.

- Ley Nacional 25612. Gestión de residuos industriales y de servicios.
- Ley Nacional 26562. Quema de pastizales.

- Ley Nacional 26331. Protección de bosques nativos.

- Ley Nacional 25916. Gestión de residuos domiciliarios.

- Ley Nacional 25841. Acuerdo Marco sobre Medioambiente del MERCOSUR.

- Ley Nacional 25831. Acceso a la información pública ambiental.

- Ley Nacional 25743. Protección del patrimonio arqueológico.

- Ley Nacional 25688. Régimen de Gestión Ambiental de Aguas.

- Ley Nacional 25675. Residuos Peligrosos y Actividades de Servicios.

- Ley Nacional 25670. Gestión de policlorobifenilos (PCB).

- Ley Nacional 25612. Presupuestos mínimos de gestión de residuos industriales y de servicios.

- Ley Nacional 25577. Prohibición de la caza de cetáceos en todo el territorio nacional, el mar territorial, la zona económica exclusiva y las aguas interiores.

- Ley Nacional 25463. Declaración de la Panthera onca como Monumento Natural, también conocida como yaguareté, yaguar, tigre overo u onça pintada.

- Ley Nacional 25438. Aprobación del Protocolo de Kyoto de la Convención Marco de Naciones Unidas sobre Cambio Climático.

- Ley Nacional 25052. Prohibición de cazar orcas en territorio nacional.

- Ley Nacional 25018. Residuos radioactivos.

- Ley Nacional 24922 Federal de pesca.

- Ley Nacional 24702. Establecimiento de diversas especies como Monumentos Naturales.

- Ley Nacional 24701. Convención sobre Lucha contra la Desertificación en los países afectados por Sequía o Desertificación, su aprovechamiento y uso racional. 
- Ley Nacional 24375. Aprobación del Convenio sobre la Diversidad Biológica.

- Ley Nacional 24295. Aprobación de la Convención Marco de las Naciones Unidas sobre Cambio Climático.

- Ley Nacional 24051. Residuos peligrosos. Generación, manipulación, transporte y tratamiento.

- Ley Nacional 23919. Aprobación del Convenio Relativo a los Humedales de Importancia Internacional, especialmente como Hábitat de Aves Acuáticas.

- Ley Nacional 23582. Convenio para la conservación y manejo de la vicuña.

- La Ley 2786 o «Ley Sarmiento». Prohibición de malos tratos a los animales.

- Ley Nacional 22421. Protección y conservación de la fauna silvestre.

- Ley Nacional 22351. Parques, Reservas y Monumentos Nacionales.

- Ley Nacional 22344. Convención sobre el Comercio Internacional de Especies Amenazadas de Fauna y Flora Silvestre.

- La ley Nacional 14346. Protección de los animales contra actos de crueldad. Se refiere a la defensa de los animales. Establece las penas que se aplicarán para quienes cometan malos tratos o actos de crueldad contra los animales.

\section{b. Decretos}

- Decreto Nacional 1347/97. Autoridad de aplicación de la Ley sobre Diversidad Biológica.

- Decreto Nacional 666/97. Conservación de la fauna silvestre.

- Decreto Nacional 522/97. La Ley 22344 y el decreto reglamentario alcanzarán al comercio de todas las especies tal como se definen en la Convención sobre el Comercio Internacional de Especies Amenazadas de Fauna y Flora Silvestres.

\section{c. Resoluciones}

- Resolución E 151/2017. Ley Nacional 25841. Acuerdo Marco sobre Medioambiente del MERCOSUR.

- Resolución 1030/04. Determinación de los nuevos índices de calificación de las especies de anfibios, reptiles y mamíferos autóctonos de acuerdo a lo establecido en el artículo 4. ${ }^{\circ}$ del Decreto 666/97.

- Resolución 91/03. Estrategia Nacional sobre Diversidad Biológica.

- Resolución 381/03. Modificaciones a los apéndices de la Convención sobre el Comercio Internacional de Especies Amenazadas de Fauna y Flora Silvestre. Contiene algunas modificaciones a la Ley Nacional 22344.

- Resolución 58/02. Establecimiento de un reglamento para la creación de fondos de investigación y manejo de especies silvestres.

- Resolución 220/98. Prohibición de la exportación, comercialización y el tránsito interprovincial de animales vivos, productos y subproductos de la especie guanaco.

- Resolución 620/98. Reglamentación de la exportación de productos y subproductos de la fauna silvestre con fines científicos.

- Resolución 63/86. Prohibición de la exportación, el tránsito interprovincial y la comercialización en jurisdicción federal de ejemplares vivos o subproductos de felinos autóctonos.

- Resolución 793/87. Prohibición de la exportación, el tráfico interprovincial y la comercialización en jurisdicción federal de productos y subproductos de zorrinos, pecaríes y yacarés, etc.

\section{FUNDAMENTACIÓN}

La Comisión Mundial sobre el Medioambiente y Desarrollo, ante el creciente deterioro 
del entorno, elaboró el informe Nuestro futuro común, o Informe Brundtland, del cual surge el concepto de desarrollo sostenible como aquel que satisface las necesidades de la generación presente sin comprometer la capacidad de las generaciones futuras para satisfacer sus propias necesidades, pero ese disfrute debe ser adecuado ya que no se pueden agotar los bienes presentes en detrimento de la satisfacción de las necesidades de las generaciones futuras. Al respecto, Reátegui Sánchez sostiene que

... los bienes jurídicos no son tales porque el legislador los haya catalogado abstractamente en una norma jurídica, que puede estar supeditada quizá a un evento o situación coyuntural, sino porque representan presupuestos indispensables para la vida en común. En general, los bienes jurídicos son circunstancias esenciales dadas (especialmente vitales), o finalidades que son indispensables para el individuo y su libre desarrollo en el marco de un sistema global estructurado sobre la base de esa concepción de los fines o para el funcionamiento del propio sistema (Reátegui Sánchez, s.d.).

Por su parte, Asturias afirma que

... uno de los problemas mundiales, junto con el cambio climático, es la necesidad de protección penal ambiental global, por medio del derecho internacional penal y los derechos humanos ambientales, se requiere de modo urgente la incorporación en la agenda política internacional del tema, para que los líderes mundiales asuman el gran desafío que demanda la protección penal ambiental internacional. El propósito debe consistir en evitar las graves agresiones ambientales que puedan poner en riesgo el futuro de la humanidad, afectando los derechos humanos y no humanos (Asturias, 2019).

Ahora, una vez identificado el bien jurídico protegido, podemos señalar que la protección mediante el derecho penal ambiental se impone como última ratio en su doble carácter, preventivo y represivo de las conductas potencialmente riesgosas o dañosas.

Esta nueva visión, donde el equilibrio ecológico y la calidad de vida son la esencia jurídicamente protegida y en sí misma valiosa, cumplimenta el mandato y la visión legislativa de nuestra Constitución Nacional; mientras que la ley penal comprende la protección del ambiente tipificando las conductas que atenten contra la conservación, la defensa y el mejoramiento ambiental.

En este sentido, Garros Martínez et al (2019) afirman que el Programa Justicia 2020 del Ministerio de Justicia de la Nación es un ejemplo de captación de la realidad descripta, bajo la pretensión de sentar bases organizativas, ejecutivas y judiciales de modernización, sobre todo con miras a los derechos de incidencia colectiva. Estas consideraciones, armonizadas con el fin de adecuar la normativa a las necesidades actuales de la sociedad y que resultarían inimaginables desde el pensamiento jurista antiguo, no escapan a la contemplación punitiva mayor, esto es, al derecho penal, en donde el daño ambiental es considerado desde su alteración más relevante cuando implica un riesgo inaceptable para la salud humana o la destrucción de un recurso ${ }^{3}$.

La tipificación del delito ambiental es, según Ángeles Cuadrado Ruíz,

\footnotetext{
${ }^{3}$ En este marco de avance normativo protector ambiental, existen diversas legislaciones latinoamericanas que prevén puniciones penales, como por ejemplo las de Brasil, Colombia, Nicaragua, Venezuela y Perú.
} 
... la protección del medioambiente a través del derecho penal, lo cual supone una mejor protección de los recursos naturales: agua, suelo y aire así como de la flora y la fauna, junto a la protección de la vida y la salud de las personas, tanto como de su entorno cultural y territorial, del que sin duda, el medioambiente forma parte (Cuadrado Ruíz, 2010).

\section{LA CRIMINALIZACIÓN}

El efecto disuasorio de la constitución de tipos penales está dado por varios factores:

1) La investigación en sede penal, así como las implicancias y recursos del proceso penal, tienen un mayor poder a raíz de contar con recursos y mecanismos con los que no cuenta el derecho civil o administrativo, convirtiéndolos en procedimientos más eficaces e intimidatorios.

2) Por otro lado, hay una garantía adicional de imparcialidad de la investigación, porque cambia la autoridad competente respecto de las autoridades que dieron las autorizaciones o permisos administrativos para desarrollar las actividades o proyectos.

3) Contribuye a la necesaria desaprobación social que se simboliza en la generación de preceptos y consecuentes sanciones penales, que es mayor que la que se da en sede administrativa o la compensación que pueda ordenarse en sede civil, cuando eleva las conductas disvaliosas a la categoría de delitos.

4) Finalmente, las sanciones administrativas provenientes principalmente de los órganos ambientales del Poder Ejecutivo, o las ordenadas en sede civil, en muchos casos son de carácter pecuniario o están relacionadas con el costo de la reparación ambiental ordenada $y$, por lo tanto, cobra mayor impulso el efecto disuasorio real de estas medidas, tanto cuando por ejemplo las personas que delinquen son insolventes o, por el contrario, cuando son económicamente poderosas; en estos casos la única posible disuasión es la sanción punitiva.

Es decir que la normativa penal debe reflejar los intereses nacionales surgidos en los últimos 20 años alrededor de los valores naturales y sus bienes y servicios, que impactan de manera directa en la vida y salud de las personas; porque si bien el ambiente es sujeto de derechos, la mayor o menor gravedad del ataque que se le efectúe esencialmente afecta esos valores irrenunciables y superiores (vida y salud humana), lo que demanda además la protección del ecosistema ligado a la cadena de incumbencias con tales valores.

En tal sentido, Palacios de Battiston (2000) afirma que el avance y el desarrollo industrial y tecnológico se han manifestado, a veces, como factores de perturbación del ambiente en una magnitud tal que se ha recurrido a regulaciones jurídicas, que van de lo administrativo a lo penal. Asimismo, sostiene que el derecho penal relativo al ambiente representa uno de los aspectos en los que el nuevo derecho penal manifiesta tendencias criminalizadoras, y que la tarea del legislador penal se caracteriza por la necesidad de adoptar una estrategia penal susceptible de ser traducida en derecho penal observando los límites y las exigencias impuestas por la Constitución Nacional (razonabilidad, lesividad, humanidad, máxima taxatividad, etc.).

Asimismo, Cuadrado Ruíz (2006) agrega que la ecología ha dejado de ser una mera instancia bucólica o la expresión pacifista de la contestación política. La autora entiende que esta conciencia ecológica que ha de favorecerse, ya que, para el desarrollo de una sociedad pacífi$\mathrm{ca}$, «no pocos valores éticos tienen una relación tan directa con la cuestión ambiental». En este 
sentido, indica que «la descripción que se hace en el artículo 340 del Código Penal español, sigue en los aspectos fundamentales al modelo alemán (...) la reparación del daño y del daño medioambiental ha de situarse en un primer plano de los objetivos político criminales».

\section{ANTECEDENTES PENALES}

En relación con los tipos o figuras penales propuestas en nuestro trabajo, visualizamos la necesidad de construir la ley penal necesaria e indispensable (principio de máxima taxatividad y mínima intervención de la ley represiva) para la preservación de este bien jurídico. Ello en nada obsta que exista paralelamente un sistema contravencional preventivo en cada provincia (conforme a nuestro sistema federal de organización nacional) y que ayude a prevenir delitos previstos en el código de fondo. El derecho contravencional (como otros ordenamientos intermedios), contribuirían a desalentar las infracciones menores y frenar la escalada de las conductas hacia el delito propiamente dicho. Pero, además, prevendría los mayores daños que supone el delito penal. Por otra parte, el derecho intermedio sancionador (previo a las instancias penales), tiene carácter preventivo y motivador positivo de conductas o su contrapartida, «desmotivador o disuasorio de conductas negativas lesivas».

En este punto, nos encontramos con varias alternativas, de las cuales debemos optar por la que mejor se adapte a las necesidades de protección de tal singular bien jurídico, adelantando desde ya que siempre serán perfectibles en el tiempo y, para ello, las provincias tienen todas las facultades no delegadas a la Nación. Los tipos penales podrían haber sido tanto tipos generales como tipos especiales para cada componente del ambiente, así también estos podrían haber sido tipos de daño o de resulta- do, o de peligro tanto concreto como abstracto.

Ossorio (2013), en su Diccionario de ciencias jurídicas, políticas y sociales, afirma que las leyes penales en blanco son aquellas normas cuyo precepto es indeterminado en su contenido — que deberá ser llenado por otra ley o reglamento- - y en las que solamente está fijada la sanción, consideramos que el uso de tales tipos en blanco (aunque restringido) resultan de toda necesidad en ciertos supuestos; ya que de otro modo nos encontraremos con tipos penales cuyo elemento objetivo puede perder vigencia por el avance dinámico de la técnica (y así podríamos encontrarnos con mayores violaciones al orden constitucional y al principio de legalidad de los que se puede achacar al uso de la ley penal en blanco). Asimismo, nos encontramos con la posible colisión de normas administrativas y penales, adelantando nuestro criterio en favor de la superioridad de la norma penal, tanto por la estructura jerarquizada de tal cuerpo normativo (nacional) como por los principios de protección y la ratio legis de ambas normas.

\section{LA RESPONSABILIDAD PENAL DE CONSULTORES Y ESPECIALISTAS HABILITADOS PARA ESTUDIOS DE IMPACTO AMBIENTAL Y PLANES DE MANEJO}

A lo largo de todo el país encontramos estudios de impacto ambiental y planes de manejo de bosques y de residuos peligrosos, entre otros, que cuentan con consultores habilitados por la autoridad de aplicación ambiental. Estos consultores son responsables de lo declarado en los estudios de impacto ambiental, que a su vez tienen carácter de declaración jurada para la persona física y jurídica y, a ellos, como responsables técnicos de dichos estudios en conjunto con un equipo interdisciplinario, o al menos así debiera ser según señalan la ciencia y la técnica.

Omnia. Derecho y sociedad, núm. 4, 2021: 55-77 
Estos estudios a su vez son sometidos a un proceso administrativo de evaluación de impacto ambiental ante la autoridad ambiental que corresponda, y que toma los datos, procesos, cantidades, etc., consignados tanto en los documentos como en las declaraciones juradas pertinentes, y es con base en esto que se realizan los dictámenes y se emiten las autorizaciones o los permisos de inicio de obra.

En muchos casos encontramos estudios de impacto ambiental plagados de inexactitudes, falsedades u omisiones, que en muchas ocasiones son evidentes, y por lo tanto connotan una connivencia con la autoridad ambiental para emitir la autorización. En otros casos, le resulta imposible a la autoridad ambiental contradecir lo expresado en el estudio, lo cual denota una falsedad en connivencia con el titular del proyecto o el dueño de la obra, todo lo cual tiene nefastas consecuencias tanto en el ambiente mismo donde se desarrollan los proyectos o servicios, como en el clima general de la forma de hacer negocios y del enforcement de las regulaciones de habilitaciones ambientales de irreparables consecuencias dañosas, generando a veces la creencia errónea de que los estudios de impacto ambiental previos se limitan a ser un trámite administrativo y el pago de una tasa.

Por todo ello, además de la responsabilidad penal del funcionario público interviniente o del titular del proyecto, los consultores ambientales que facilitan estas situaciones y que son necesarios para generar estos documentos deben ser también penalmente responsables.

\section{a. Criterios para la construcción de los tipos penales ambientales}

Con relación a la cantidad de tipos penales construidos, existe una enorme cantidad de posibles tipos penales lesivos del medioambiente, esto es, de alternativas posibles que ofrece la legislación comparada. En función de la experiencia de las redes de fiscales y jueces, creemos que no tiene un efecto positivo la consagración de una profusa cantidad de tipos penales sino, más bien, un grupo limitado y suficientemente estructurado de tipos penales. En una posición de equilibrio, en nuestro proyecto de investigación adoptamos un criterio intermedio en la construcción de estos.

Asimismo, la reforma propuesta tiene la virtud de ordenar tipos penales consagrados en leyes especiales, pero en un solo cuerpo normativo penal, tal como es el caso de los delitos comprendidos en la Ley 24051 de residuos peligrosos, la Ley 22421 de Protección y Conservación de Fauna Silvestre, la Ley 14346 de malos tratos y crueldad hacia los animales. Además, incorporaría en el Código Penal los principios y criterios de conservación y gestión contenidos en los tratados y acuerdos internacionales contenidos en nuestra Constitución Nacional.

De esta manera podemos destacar los siguientes aspectos:

- Consagración del tipo penal del ecocidio: consideramos importante la incorporación de dicha figura, la cual implica un daño tan vasto que alcanza ribetes de delito contra la humanidad, según el Estatuto de Roma que entró en vigor en el año 2002.

- El uso del instituto del arrepentido en materia ambiental: este instituto es perfectamente posible y aplicable en materia de delitos contra el medioambiente, en especial teniendo en cuenta el ejemplo del dependiente de una empresa co-responsable de un delito cometido desde o por la persona jurídica o su directorio. Hay una cadena de responsabilidades inferior, que admite perfectamente la figura del arrepentido, con los beneficios que reportaría para la investigación y la sanción. 
- Responsabilidad de los funcionarios públicos: es una constante en el Código Penal actual el incremento de la pena para los funcionarios públicos que participen en los delitos comunes de nuestra ley penal de fondo. Existe una violación mayor al ordenamiento jurídico, cuando quien participa del hecho criminal es el encargado de velar por la paz, la seguridad o el cumplimiento de la Constitución o sus leyes inferiores, cualquiera sea su lugar de desempeño, partiendo del concepto de que el funcionario público siempre tiene un rango mayor de reproche punitivo, porque el rol y las facultades que detenta recargan su responsabilidad por hechos delictivos en general.

\section{CONCLUSIONES Y PROPUESTA DE TIPOS PENALES}

A partir de la investigación bibliográfica y legal realizada en el marco del proyecto de investigación, y teniendo en cuenta especialmente el análisis legislativo realizado en relación con el derecho comparado existente en materia de delitos ambientales contemplado en leyes y códigos penales de diversos países -análisis detallado en el informe final presentado ante el Consejo de Investigaciones de la Universidad Católica de Salta-, se ha podido elaborar una propuesta de legislación para ser incluida en el Código Penal vigente, que a continuación se desarrolla:
Título XIV. Delitos contra el medioambiente, fauna y flora

\section{Capítulo I. Ataques al medioambiente}

Artículo 314: Contaminación ${ }^{4}$, contagio y envenenamiento del medioambiente.

$\left.1^{\circ}{ }^{\circ}\right)$ Se impondrá pena de dos (2) a seis (6) años de prisión y multa de cinco (5) a quince (15) $\mathrm{SMVM}^{5}$, al que por cualquier medio contaminare o arrojare elementos líquidos, sólidos o gaseosos que resultaren contaminantes o de un modo peligrosos para la salud, en suelos, aguas, atmósfera, sistemas naturales o en el ambiente en general.

2. $\left.{ }^{\circ}\right)$ El que mediante emisiones, vertidos, radiaciones, extracciones o excavaciones, soterramientos, ruidos, vibraciones, inyecciones o depósitos, en la atmósfera, el suelo, el subsuelo o las aguas terrestres, subterráneas o marítimas, incluido el alta mar, con incidencia incluso en los espacios transfronterizos, así como las captaciones de aguas que, por sí mismos o conjuntamente con otros, causare o pudiere causar daños sustanciales a la calidad del aire, del suelo o de las aguas, o a animales o plantas, violando leyes o reglamentos establecidos a fin de evitar los daños antes descritos.

$\left.3^{\circ}{ }^{\circ}\right)$ El que por cualquier medio diseminare enfermedad, plaga, especies biológica o genéticamente alteradas con grave peligro para la salud humana, o de mortandad de animales o de alteración o destrucción significativa de la flora o fauna, violando leyes o reglamen-

\footnotetext{
4 «Contaminación» supone para esta disposición: alterar el carácter o naturaleza de la sustancia que se trate (agua, aire o tierra), de modo que sea alterada, inutilizada, arruinada o dañada total o parcialmente de manera peligrosa para la salud de seres vivos, aunque dicho daño o sus secuelas sean temporarios o aun reparables. La diferencia de estos delitos cotejados con los estragos que se describen en los artículos 197 y siguientes, es que en aquel caso hay daños causados dolosamente sin ninguna otra exigencia. En cambio, este articulado responde a quienes a raíz de alguna actividad cualquiera o que fuera reglada o que conocen reglamentada de alguna forma, violan tales normas y causan los desastres que se enuncian con perjuicio para el medioambiente, entendido como sustento vital para seres vivos y cuya alteración resulte efectivamente peligrosa para la salud, desarrollo o preservación de seres vivos o causare efectivamente daños irreparables.
}

${ }^{5}$ Salario mínimo, vital y móvil. 
tos establecidos a fin de preservar evitar las conductas antes descritas sufrirá la pena de dos (2) a ocho (8) años de prisión y multa de cinco (5) a veinte (20) SMVM.

Artículo 315: Desechos y materiales peligrosos.

1. ) El que arroje, deposite, vierta, oculte o comercialice desechos provenientes de actividades industriales, comerciales o de servicios, líquidos sólidos o gaseosos poniendo en peligro la vida humana y/o siendo no asimilables por el medioambiente, o no cumpla las normas sanitarias y de protección ambiental, sufrirá la pena de privación de libertad de tres (3) a seis (6) años de prisión y multa de quince (15) a ciento cincuenta (150) SMVM.

2. $\left.{ }^{\circ}\right)$ Modalidad culposa. Si el hecho se cometiera por alguna de las formas de culpa, la pena se reducirá a la mitad del mínimo y máximo.

Artículo 316: Agravantes y atenuantes.

$\left.1 .^{\circ}\right)$ Se impondrá pena de cuatro (4) a diez (10) años de prisión y multa de 10 a 100 SMVM cuando los hechos descritos en este Título:

a) Inutilizaren de manera permanente el suelo, aguas, atmosfera o hábitat para la ocupación o asentamiento humano, sea en un área urbana o rural por más de un año.

b) Provocaren el desplazamiento, aunque fuere temporal, de los habitantes de las áreas afectadas.

d) Causaren daños directos a la salud de la población.

e) Provocaren la interrupción del abastecimiento público de elementos líquidos, gaseosos o sólidos que resulten indispensables para la vida o el desarrollo humano o para la vida y desenvolvimiento de una comunidad por más de 72 horas.

$\left.2 .^{\circ}\right)$ La pena será de seis (6) a veinte (20) años de prisión si se produjeren lesiones graves o gravísimas a dos o más personas, como consecuencia de los hechos precedentemente descriptos.

3. ') La pena será de diez (10) a treinta (30) años de prisión, si como consecuencia de los hechos descritos resultare la muerte de una (1) a cinco (5) personas.

La pena se elevará de quince (15) a cuarenta (40) años cuando la muerte fuere de más de 5 (cinco) personas.

La pena será de prisión o reclusión perpetua si las muertes resultantes superaran las cincuenta (50) personas.

4..$\left.^{\circ}\right)$ Modalidad culposa. Cuando los hechos contemplados en los incisos anteriores se cometieren por imprudencia, negligencia u otras formas de culpa, las escalas de las respectivas penas allí contempladas se reducirán a un tercio del mínimo y hasta la mitad del máximo. En caso de prisión perpetua, la pena será de quince (15) a veinticinco (25) años de prisión y multa de mil (1000) a cinco mil (5000) SMVM.

5..$^{\circ}$ Personas jurídicas. Si los delitos mencionados se hubieren cometido mediante o desde personas jurídicas éstas serán sancionadas con multa de cinco mil (5000) a cincuenta mil (50 000) SMVM, sin perjuicio de la responsabilidad personal de sus directores, gerentes, otras autoridades o directivos.

Si estuvieren dedicadas inequívocamente a estas actividades ilícitas o llevaren a cabo las conductas en forma reiterada, podrán ser clausuradas definitivamente y las multas se elevarán al doble de su mínimo y máximo, respectivamente ${ }^{6}$.

\footnotetext{
${ }^{6}$ La presente disposición y las sucesivas resultan figuras independientes de las previstas en el capítulo de «Grandes estragos», delitos cuya criminalidad y dolosidad resultan muy diversos de los contemplados en esta especie de delitos, que por ello conllevan penas muy inferiores. La contaminación, como otros atentados al agua, flora y fauna que
} 
Artículo 317: Residuos tóxicos y otros materiales peligrosos.

1. $\left.{ }^{\circ}\right)$ El que en violación a leyes, reglamentos $\mathrm{u}$ otras normas atinentes, autorice, permita, coopere o ejecute por sí o por terceros el depósito, o de cualquier manera participe en la introducción, fabricación, manipulación, distribución o transporte en territorio nacional de materiales o desechos radioactivos y otros de origen interno o externo, que por sus características constituyan un peligro para la salud de la población y el medioambiente, será sancionado con la pena de prisión de tres (3) a ocho (8) años y multa de quince (15) a ciento cincuenta (150) SMVM.

Igual pena sufrirá el que transfiera e introduzca tecnología contaminante no aceptada en el país, o que pueda producir daños en el cuerpo o en la salud de personas indeterminadas.

$\left.2^{\circ} .^{\circ}\right)$ Responsabilidad culposa. Si las conductas descritas en todas las disposiciones anteriores se cometieran por alguna forma de culpa, las penas se reducirán a la mitad del mínimo y máximo.

Artículo 318: Responsabilidad funcional y profesional.

1. $\left.{ }^{\circ}\right)$ Será penado con prisión de uno (1) a seis (6) años e inhabilitación especial de dos (2) a diez (10) años el funcionario público, perito o consultor oficial, sea que fuere convocado o contratado por la autoridad de cualquier clase, que, a sabiendas de su irregularidad, emitiere informes falsos, adulterados, parciales o de cualquier modo favoreciendo a la concesión de licencias o permisos para llevar a cabo actividades contaminantes o perjudiciales previstas en el presente Título.

$\left.2 .^{\circ}\right)$ Las mismas penas se impondrán al funcionario fiscalizador que, habiendo tomado conocimiento de esas actividades, las hubiere ocultado o tolerado o encubierto.

3. $\left.{ }^{\circ}\right)$ Responsabilidad culposa. Si algunos de los sujetos mencionados en los dos artículos precedentes hubieren obrado por cualquiera de las formas de culpa, las penas mencionadas se reducirán a la mitad de su mínimo y máximo.

\section{Capítulo II. Explotación ilegal de recursos naturales mineros}

Artículo 319: $\left.1 .^{\circ}\right)$ Será reprimido con pena privativa de libertad de cuatro (4) años a seis (6) años y con cien (100) a trescientos (300) SMVM el que realice actividad de exploración, extracción, explotación u otros actos similares, de recursos minerales, metálicos o no metálicos, sin contar con la autorización de la entidad administrativa competente, que cause o pueda causar perjuicio, alteración o daño al ambiente o a sus componentes, a la calidad

se describen en estas figuras, son producto de violación a leyes o reglamentaciones en actividades que pueden entrañar riesgo de desastre para el medioambiente. Distinto al estrago, que está previsto como un delito personal/individual doloso o culposo de daño directo a bienes similares, pero provocado con medios estragosos o que escapan al dominio del autor y que pueden ser cometidos por cualquier persona. En el presente capítulo se contempla específicamente a sujetos calificados o actividades especiales (como la minera, farmacológica, industrial, agrícola-ganadera, de caza, de pesca, turística u otras similares), sujetas a reglamentaciones cuya violación pueden conducir a resultados estragosos similares pero a una escala de mayor reproche y, por otra parte, circunscriptos en tiempo, modo y lugar. Asimismo incluimos en este capítulo el maltrato a animales y atentados menores a la flora, porque también se refieren a la acción particularizada de individuos determinados, respecto de objetos de delito igualmente determinables. Distinto al caso de los estragos, en que las consecuencias de la conducta se tornan incontrolables y el daño es dirigido multidireccionalmente, sin importar su alcance. 
ambiental o a la salud ambiental.

2. $\left.{ }^{\circ}\right)$ Modalidad culposa. Si el agente actuó por culpa, la pena será privativa de libertad no mayor de tres (3) años o con prestación de servicios comunitarios de cuarenta (40) a ochenta (80) jornadas.

Artículo 320: La pena será de cuatro (4) a diez (10) años de prisión y multa de cien (100) a quinientos (500) SMVM, cuando el delito previsto en el anterior artículo se cometiera en cualquiera de los siguientes supuestos:

1. En zonas totalmente vedadas para el desarrollo de actividad minera.

2. En áreas naturales protegidas, o en tierras de comunidades nativas, campesinas o indígenas o parques o reservas naturales nacionales, provinciales o municipales.

3. Utilizando dragas, artefactos u otros instrumentos similares.

4. Si el agente empleara instrumentos $u$ objetos capaces de poner en peligro la vida, la salud o el patrimonio de las personas.

5. Si se afectaran sistemas de irrigación o aguas destinados al consumo humano.

6. Si el agente se aprovechara de su condición de funcionario o servidor público.

7. Si el agente empleara para la comisión del delito a menores de edad u otra persona inimputable.

Artículo 321: El que financiare la comisión de cualquiera de los delitos previstos en este Título será reprimido con pena privativa de libertad de cuatro (4) a ocho (8) años y multa de doscientos cincuenta (250) a seiscientos cincuenta (650) SMVM. La pena se elevará al doble, cuando se financiara cualquiera de tales delitos en sus formas agravadas previstas.

Artículo 322: El que obstaculizare o impidiere la actividad de evaluación, control y fiscalización de la autoridad administrativa relacionada con la minería ilegal, o llevare a cabo el tráfico ilícito de insumos químicos y maquinarias destinados a explotar la minería ilegal, será reprimido con pena privativa de la libertad de uno (1) a seis (6) años y multa de cincuenta (50) a quinientos (500) SMVM.

\section{Capítulo III. Delitos contra la fauna}

Artículo 323: Depredación. Pesca y caza ilegal.

1. ${ }^{\circ}$ Se impondrá prisión de seis (6) meses a tres (3) años y multa de cinco (5) a cincuenta (50) SMVM, con más inhabilitación de tres (3) a diez (10) años al que cazare, pescare, atrapare o matare integrantes de cualquier especie animal, contraviniendo leyes o reglamentos atinentes a dichas actividades.

2. ) Serán especialmente casos incluidos y se agravará el mínimo de pena a un (1) año, cuando tales conductas se llevaren a cabo respecto de:

a) Animales de fauna silvestre o acuática en período de veda o reproducción.

b) Animales de especies protegidas o que estuvieren amenazadas o en peligro de extinción, en cualquier tiempo.

c) En lugares expresamente prohibidos o protegidos.

d) Con medios prohibidos por la ley o por su naturaleza gravemente dañosa.

3. ') La misma pena se impondrá al que, en violación de leyes o reglamentos:

a) Impidiere o dificultare la reproducción o migración de animales de la fauna silvestre, acuática o de una especie declarada en peligro de extinción.

b) Alterare o procurare alterar genéticamente una especie silvestre, acuática o declarada en peligro de extinción.

c) Dañare o destruyere un nido, un refugio o un criadero natural que estuvieren utilizando las especies respectivas, o se alterare su hábitat. 
d) Matare a cualquier animal propio de los lugares protegidos.

4. $\left.{ }^{\circ}\right)$ Agravantes: el máximo de la pena de prisión será de cinco (5) años y el de multa de ciento cincuenta (150) SMVM, con más inhabilitación de cinco (5) a veinte (20) años, cuando se emplearen métodos, instrumentos o medios prohibidos por la ley o los reglamentos, que ocasionaren grandes estragos en la especie de la fauna silvestre o acuática o del área protegida por la ley o los reglamentos.

5.) Personas jurídicas. Cuando cualquiera de las conductas antes mencionadas fuere ejecutada por organizaciones, empresas, bandas o asociación de personas provenientes de otros países en el territorio nacional o en la zona aérea o marítima exclusiva sometida a la soberanía del Estado nacional, las penas se elevarán de cuatro (4) a veinte (20) años de prisión, multa de cien (100) a diez mil (10 000) SMVM y decomiso de naves, aeronaves u otros medios de transporte empleados, como así también inmuebles y demás elementos utilizados para cometer el delito o alojar o transportar a los partícipes, teniendo en cuenta para fijar la pena, la extensión del perjuicio causado y el modo de realización del hecho y medios empleados para su comisión.

Si se hubiere producido resistencia armada o uso de armas de cualquier clase contra la autoridad interviniente o los particulares que hubieren intervenido en auxilio de ellas, las penas se elevarán en un tercio de su mínimo y máximo, respectivamente.

Artículo 324: Maltrato a animales ${ }^{7}$.

1. $\left.{ }^{\circ}\right)$ Será penado con prisión de seis (6) meses a dos (2) años y multa de cinco (5) a veinte (20) SMVM, el que infligiere malos tratos o hiciere víctima de actos de crueldad a los animales.
2. $\left.{ }^{\circ}\right)$ Se considerarán actos de maltrato:

a) No alimentar a los animales domésticos o cautivos.

b) Azuzarlos para el trabajo mediante instrumentos que, no siendo de simple estímulo, les provocaren innecesarios sufrimientos o dolores.

c) Abusar de su empleo en el trabajo sin darles ocasión de reponerse, conforme a las condiciones ambientales, o hacerlo cuando no se hallaren en condiciones adecuadas.

d) Estimularlos con drogas sin perseguir fines terapéuticos.

3. $\left.{ }^{\circ}\right)$ Se considerarán actos de crueldad, sin perjuicio de todo aquel que produzca sufrimiento manifiesto:

a) Practicar la vivisección cuando no sea estrictamente necesario por razones de investigación científica, o cuyos resultados conocidos se hayan obtenido con prácticas anteriores.

b) Mutilar cualquier parte del cuerpo de un animal, salvo con fines de mejoramiento, marcación o higiene de la respectiva especie, o por razones terapéuticas.

c) Intervenir animales domésticos sin anestesia.

d) Intervenir animales quirúrgicamente sin poseer el título de médico o veterinario, salvo casos de necesidad o urgencia o con fines terapéuticos o cuando fuera practicado con fines de perfeccionamiento técnico operatorio.

e) Experimentar con animales de grado superior en la escala zoológica al indispensable según la naturaleza de la experiencia.

f) Abandonar a sus propios medios a los animales utilizados en experimentos.

g) Golpearlos, encerrarlos o amarrarlos por tiempo prolongado, innecesariamente.

4. ${ }^{\circ}$ ) La pena se incrementará en el doble del mínimo y máximo antes indicados, cuando los actos consistan en:

\footnotetext{
${ }^{7}$ Algunas de estas conductas podrían considerarse contravención grave, como ocurre en algunas provincias.
} 
a) Matar innecesariamente animales grávidos, cuando tal estado fuere patente en el animal.

b) Lastimar o arrollar dolosamente animales, causarles torturas o sufrimientos innecesarios, o matarlos de modos crueles o dolorosos cuando no existieren motivos razonablemente atendibles.

c) Realizar actos públicos o privados de riña de animales, corridas de toros, novilladas o cualquier otro en que se mate o hiera gravemente a los animales.

\section{Capítulo IV. Delitos contra la flora}

Artículo 325: Atentados contra la flora y su ecosistema ${ }^{8}$.

$1^{\circ}$ ) Será penado con prisión de seis (6) meses a tres (3) años y multa de diez (10) a doscientos (200) SMVM, el que en violación de lo dispuesto por leyes o reglamentos respecto de las especies de la flora silvestre o acuática:

a) Extrajere o utilizare ejemplares en cantidad no autorizada.

b) Alterare la especie.

c) Impidiere o dificultare su procreación.

d) Comerciare o de cualquier forma se beneficiare de los especímenes, restos, productos o partes de sus recursos genéticos.

2..$^{\circ}$ La pena se incrementará en el doble de su mínimo y máximo al que sin autorización o excediendo la que tuviere, o violando disposiciones legales o reglamentarias u órdenes legítimas de la autoridad:

a) Talare bosques o tierras forestales, para fines distintos al uso doméstico.

b) Extrajere o explotare recursos del subsuelo $u$ otros componentes del suelo en áreas forestales. c) Creare, modificare, alterare o eliminare cursos o espejos hídricos, extrajere áridos de cuencas o microcuencas, drenare pantanos, cenagales u otros espacios húmedos de tierras forestales.

3. ) El máximo de la pena será de ocho (8) años cuando el delito fuere cometido:

a) En el periodo de caída de las semillas, de formación de vegetaciones, o en época de sequía o inundación.

b) Contra especies protegidas de la flora silvestre o acuática.

c) Con métodos, instrumentos o medios prohibidos capaces de provocar estragos en la especie de la flora silvestre o acuática, o del área protegida.

Artículo 326: Delitos mayores contra la flora. Se impondrá pena de cuatro (4) a dieciséis (16) años y multa de quince (15) a doscientos cincuenta (250) SMVM, cuando se ocasionare daño a cualquier formación vegetal sea nativa o generada por forestación o plantación con cualquier finalidad, que por su extensión, gravedad, alcance, irreparabilidad o irrecuperabilidad, alcance proporciones de desastre definitivo, o cuya recuperación demande más de cinco (5) años, o produzca desertificación, sequía definitiva o la ruina de zona o región determinada o grave e irreparable alteración de su flora o de su fauna.

Artículo 327: Responsabilidad de los consultores ambientales. A las personas responsables técnicas de los estudios de impacto ambiental, así como de los planes de manejo y demás documentos y estudios técnicos que introduzcan falsedades u omisiones graves en los estudios y documentos que dan lugar a autorizaciones o permisos de obras, se les

\footnotetext{
${ }^{8}$ Los denominamos de este modo, porque los atentados mayores se incluyeron en «Grandes estragos». Sin perjuicio de ello, en el inciso $4 .^{\circ}$ ) del art. 214 se refuerza la protección penal.
} 
impondrá la misma pena de la falsificación de documentos públicos.

Finalmente, reiteramos y destacamos que nuestra propuesta comprende todas aquellas situaciones o conductas que merecen ser reprochadas por la legislación penal de fondo, porque se halla en juego el interés de toda la Nación y sus habitantes, formando parte del derecho penal común, sin perjuicio de las legislaciones preventivas y complementarias que cada jurisdicción provincial pueda dictar en la materia.

Por todo lo expuesto, se pretende que nuestro trabajo de investigación sea elevado ante las autoridades legislativas nacionales, en aras de contribuir a la realización de un aporte a la protección jurídica del medioambiente.

\section{REFERENCIAS BIBLIOGRÁFICAS}

Asturias, M. A. (2018). Crímenes, delitos o graves agresiones ambientales nacionales e internacionales. Ciudad Autónoma de Buenos Aires: Cathedra Jurídica.

Asturias, M. A. (2019). El crimen ambiental y la necesidad de protección internacional. Recuperado de: https://www.perfil.com/ amp/noticias/opinion/opinion-miguel-angel-asturias-crimen-ambiental-y-la-necesidad-de-proteccion-internacional.phtml [Consulta: 18 de noviembre de 2020]

Brañes, R. (2000). Manual de derecho ambiental mexicano. México: Fondo de Cultura Económica.

Cuadrado Ruiz, M. A. (2006). Consecuencias jurídicas en los delitos contra el medioambiente.
Derecho penal ambiental. Madrid: Exlibris Ediciones.

Cuadrado Ruiz, M. A. (2010). Derecho y medioambiente. Revista Electrónica de Derecho Ambiental n. ${ }^{\circ} 21$. Recuperado de: https://huespedes.cica.es/gimadus/21/03 derecho_y_medioambiente.html [Consulta: 18 de noviembre de 2020]

Garros Martínez, M. C.; Torres Fernández, R. I.; Martínez, M. C.; Safar, E. (2019). Delitos ambientales. Revista de Derecho Ambiental n. ${ }^{\circ}$ 60 , edición $15 .^{\circ}$ aniversario. Buenos Aires: Abeledo Perrot.

Libster, M. (1993). Delitos ecológicos. Buenos Aires: Ediciones Depalma.

Libster, M.; Crea, J. (2019). Derecho penal ambiental. El acceso a la Justicia y la integración a los Objetivos del Desarrollo. Ciudad Autónoma de Buenos Aires: Ediciones Cathedra Jurídica.

Ossorio, M. (2013). Diccionario de ciencias jurídicas, políticas y sociales. Buenos Aires: Heliasta.

Palacios de Battiston, C. R. (2000). Delitos ambientales. Córdoba: Francisco Ferreyra Editores.

Prieur, M. (2012). El nuevo principio de no regresión en derecho ambiental. Editorial Bruylant.

Reategui Sánchez, J. (s.d.). Consideraciones sobre el bien jurídico tutelado en los delitos ambientales.

Recuperado de: https://huespedes.cica.es/gimadus/11/consideraciones.htm [Consulta: 18 de noviembre de 2020].

Valls, M. F. (2008). Derecho ambiental. Buenos Aires. Editorial Abeledo Perrot. 